\title{
Small hybrid solar power system
}

\author{
M. Kane ${ }^{\text {a }}$, D. Larrain ${ }^{\text {a }}$, D. Favrat ${ }^{\mathrm{a}, *}$, Y. Allani ${ }^{\mathrm{b}}$ \\ ${ }^{a}$ Laboratory for Industrial Energy Systems (LENI), Institute of Energy Sciences, Swiss Federal Institute of \\ Technology of Lausanne (EPFL), CH1015 Lausanne, Switzerland \\ ${ }^{\mathrm{b}}$ COGENER, Science Park, Swiss Federal Institute of Technology of Lausanne, CH1015 Lausanne, Switzerland
}

Received 12 July 2002

\begin{abstract}
This paper introduces a novel concept of mini-hybrid solar power plant integrating a field of solar concentrators, two superposed Organic Rankine Cycles (ORC) and a (bio-)Diesel engine. The Organic Rankine Cycles include hermetic scroll expander-generators ${ }^{1}$ and the sun tracking solar collectors are composed of rows of flat mirror bands (CEP) arranged in a plane, that focus the solar energy onto a collector tube similar to those used in SEGS plants in California. Waste heat from both the exhaust gases and the block cooling of the thermal engine are also heat sources for the ORCs. Such units meet electricity, cooling and pumping needs of remote settlements. The thermal engine guarantees a minimum level of both power and heat availability at night or during cloudy periods. Laboratory tests, made with the superposed ORCs only, confirmed adequate operational characteristics with good performances over a broad range of conditions. A few preliminary tests on the site of the solar power plant when coupled with the engine confirmed a reasonable behavior and the interest of the concept even at part load or during sharp variations of the thermal supply.
\end{abstract}

(C) 2003 Elsevier Ltd. All rights reserved.

\section{Introduction}

Drawbacks of solar power generation are:

- the low density of solar radiation requiring large collector areas,

- high investment costs partly due to the use of specific technologies produced in small series, and

\footnotetext{
* Corresponding author. Tel.: +41-21-693-2511; fax: +41-21-693-3502.

E-mail addresses: daniel.favrat@epfl.ch (D. Favrat); cogener@epfl.ch (Y. Allani).

1 The word expander is often used to characterize units recovering the expansion energy of a gas, in particular when based on a volumetric machine. The word turbine or expander will be used indifferently in this paper.
} 


\section{Nomenclature}

HSPS hybrid solar power system

ISCCS Integrated Solar Combined Cycle System

ISFPP Integrated Solar-Fossil Power Plants

LHV lower heating value $(\mathrm{kJ}$ or $\mathrm{kJ} / \mathrm{kg}$ )

ORC Organic Rankine Cycle

PAESI Projet Pilote d'Aménagement Energétique Solaire Intégré

SEGS solar electric generating system

SPS solar power system

$\dot{E}_{\mathrm{M}} \quad$ electric power delivered by the motor engine (kWe)

$\dot{E}_{\mathrm{P}} \quad$ electric power delivered to the pump (kWe)

$\dot{E}_{\mathrm{T}} \quad$ electric power delivered by the turbine $(\mathrm{kWe})$

$G \quad$ direct solar radiation $\left(\mathrm{W} / \mathrm{m}^{2}\right)$

$\dot{M}_{\text {ho }} \quad$ heating oil mass flow of the hot source $(\mathrm{kg} / \mathrm{s})$

$\dot{M}_{\mathrm{pw}} \quad$ pressurized water mass flow of the hot source $(\mathrm{kg} / \mathrm{s})$

$\dot{M}_{\text {cw }} \quad$ coolant water mass flow from the engine to the preheater $(\mathrm{kg} / \mathrm{s})$

$\dot{M}_{\mathrm{f}} \quad$ fuel mass flow rate $(\mathrm{kg} / \mathrm{s})$

$P \quad$ pressure $(\mathrm{kPa})$

$T$ temperature $\left({ }^{\circ} \mathrm{C}\right.$ or $\left.\mathrm{K}\right)$

$T_{\mathrm{c}} \quad$ temperature of the cold water cooling the condenser (K)

$T_{\mathrm{cw}} \quad$ temperature of the engine coolant water heating the preheater $(\mathrm{K})$

$T_{\text {eg }}$ temperature of exhaust gases at the outlet of the gas exchanger $(\mathrm{K})$

$T_{\mathrm{g}} \quad$ temperature of exhaust gases from the motor engine (K)

$T_{\text {in }} \quad$ stream inlet temperature $(\mathrm{K})$

$T_{\text {out }} \quad$ stream outlet temperature $(\mathrm{K})$

$T_{\mathrm{pw}} \quad$ temperature of the pressurized water heating the evaporator $(\mathrm{K})$

$T_{\mathrm{s}} \quad$ temperature of the pressurized water at the outlet of the collector $(\mathrm{K})$

$\dot{W} \quad$ heat rate (power-transformation) associated to a hot source heating the ORCs (kWth)

$\dot{W}_{\text {ho }} \quad$ heat rate (power-transformation) associated to the hot oil heating the evaporator (kWth)

$\dot{W}_{\mathrm{cw}} \quad$ heat rate (power-transformation) associated to the engine coolant water heating the preheater $(\mathrm{kWth})$

$\dot{W}_{\text {pw }} \quad$ heat rate (power-transformation) associated to the pressurized water heating the evaporator ( $\mathrm{kWth})$

$\Delta h_{\mathrm{ho}} \quad$ enthalpy difference on the hot oil heating the evaporator $(\mathrm{kJ} / \mathrm{kg})$

$\Delta h_{\mathrm{cw}} \quad$ enthalpy difference on the engine coolant water heating the preheater $(\mathrm{kJ} / \mathrm{kg})$

$\Delta h_{\mathrm{pw}}$ enthalpy difference on the pressurized water heating the evaporator $(\mathrm{kJ} / \mathrm{kg})$

$\Delta k_{\mathrm{cw}}$ coenthalpy difference (exergy) of the coolant to the preheater $(\mathrm{kJ} / \mathrm{kg})$ 


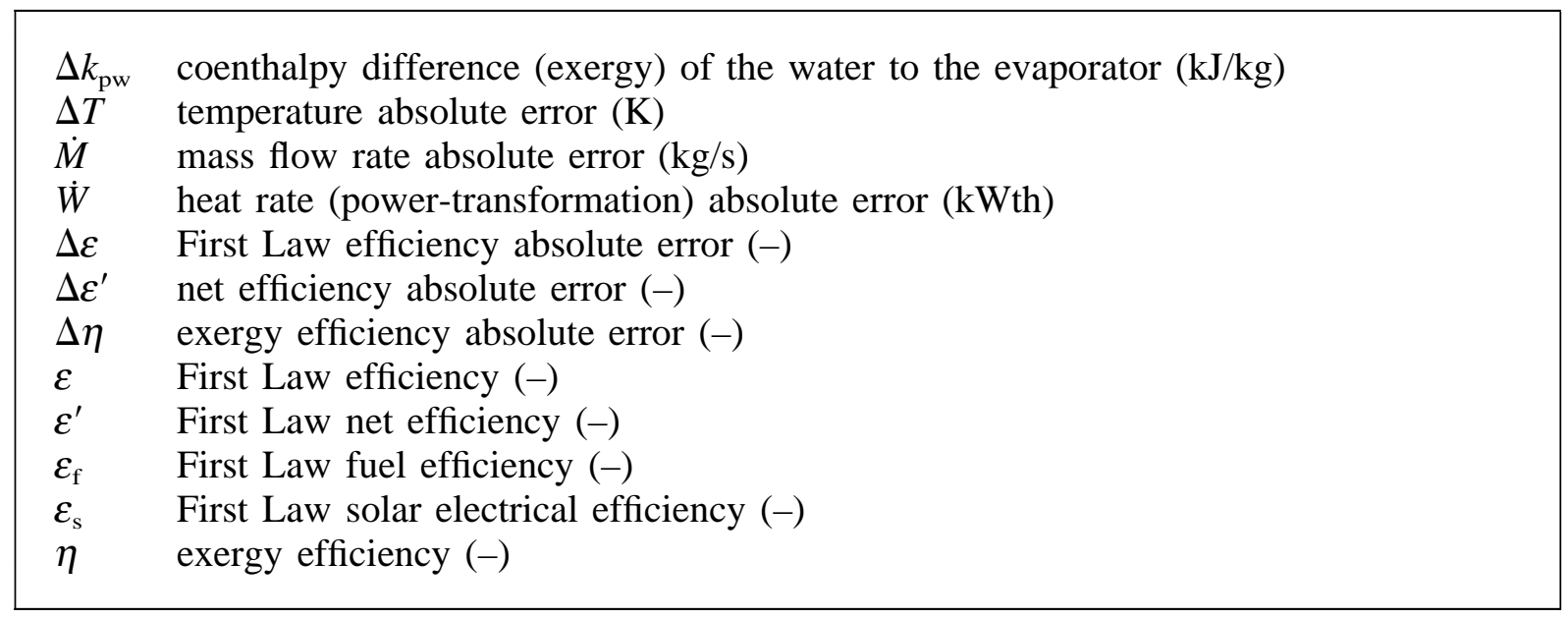

- the lack of reliability and the fluctuations of the solar supply, which are highly dependent on the meteorological conditions.

Recent technological progress opens new perspectives for Integrated Solar Fossil Cycle Systems (ISFCS). In the context of increasing global environmental concerns, these perspectives offer the possibility of accelerating fossil fuel substitution (even if only partial), and therefore reducing emissions, while ensuring an adequate power availability [1,2].

On the basis of classical thermo-economic criteria (performance/cost), several integration options are commonly cited [3], which include:

- the SEGS power plants in California [4] with electric powers between 30 and $80 \mathrm{MWe}$, which are based on cylindro-parabolic concentrators with additional fossil fuel burners or natural gas boilers to supply a steam cycle,

- the Integrated Solar Combined Cycle Power System (ISCCS), such as PAESI [5-7] or ISSCSNevada, USA [8,9] based on efficient combined cycles with a better fuel conversion efficiency and reduced electricity production costs (by as much as 42\%) compared to the present SEGS plants [4], and

- concepts using high efficiency parabolic solar concentrators, delivering solar heat at an exergy level sufficient to preheat or to fully heat the compressed air of the gas turbine of a combined cycle or to supply heat for endothermic fuel reforming [10].

It is important to note that these advanced concepts have been designed for multi-megawatt plants aiming at a centralized production, with the associated power transport losses and costs, and with limited possibilities to use the waste heat (cogeneration to meet either heat and/or cold demand). A small concept of hybrid solar power unit called SSPRE (Solar Steam Power Rankine Engine) is mentioned in [11,12]. This concept is normally designed to work in solar mode and could not efficiently guarantee energy services when solar radiation is not available because the fuel is essentially used to superheat steam produced at low pressure (about $100 \mathrm{kPa}$ ) by low temperature solar collectors. This paper presents a small hybrid solar power system (HSPS) of a 
few $\mathrm{kWe}$ to a few tens of $\mathrm{kWe}$, with fuel night operation modes and easy cogeneration opportunities for hot water production, absorption refrigeration or thermal desalination. A small hybrid prototype of a power plant of 10-25 $\mathrm{kWe}$ has been designed and implemented in the frame of a project called SPS (solar power system). This plant integrates two rows of solar collectors, two superposed ORC equipped with a scroll hermetic expander-generator, and a heat engine. The sun tracking linear solar concentrators consist of flat concentrators made of series of thin plate mirrors (CEP) focusing solar energy on vacuum insulated focal tubes (SEGS type), in which the thermal fluid (pressurized water) circulates. In hybrid mode, additional heat is supplied by heat recovery from the exhaust gases of the engine in series with the solar network and by a separate network recovering heat from the cooling of the engine block at an intermediate temperature level. The nominal electric power of the engine is $15 \mathrm{kWe}$. This paper discusses the design parameters and options, the results of laboratory measurements of the power unit subsystem and the preliminary in situ demonstration of the full plant.

\section{Design of the SPS prototype}

In a hybrid solar thermal power plant, the electricity production efficiency is strongly dependent on the way the fossil fuel unit is integrated. The term hybrid is often used to characterize such systems and the solar production part of the total electricity production is a design parameter. It can go from a relatively small proportion (5-15\%) in the large ISCCS currently planned, to a significant part if the plant can be shut down during part of the night. Independent from the night operational strategy adopted, the integration of an engine allows:

- a leveling of the heat supply in spite of solar radiation fluctuations,

- a faster startup by preheating of the solar network in engine cogeneration mode, and

- an extension of the hours of operation of the solar part late in the afternoon when the solar radiation decreases.

A major difficulty when using standard components for the power unit is the different exergy levels of the heat sources. An additional problem is the large number of parameters linked to the choice of the operational sequences to meet a given demand. It complicates the design and optimization of these systems (a structured thermoeconomic optimization was done lately which will be published separately [13]). Since the main application target was to supply energy services to isolated villages, the preference was given to using hermetic components for the ORCs that allow a factory charge of working fluid and reduce the on-site maintenance needed.

The design is a tradeoff between:

- the percentage of solar versus fossil fuel energy supply for a given demand and environmental objectives,

- the increase of the thermodynamic cycle efficiency, the expander characteristics and the increased losses of the solar collectors as collector temperature raises, and

- the energetic efficiency and the control complexity (reliability, robustness, cost, training requirements, etc.). 
For the SPS project decision was made to rely on earlier work [14], which demonstrated the use of expanders modified from standard hermetic scroll compressor units with potentially low costs as most components are produced by thousands worldwide [1,2]. The major limitations of the latter are the limited pressure range and the built-in volume ratio for efficient operation. Hence the proposal to preferably use two superposed ORCs each working with a different fluid, which allows to work:

- at a range of pressure levels and pressure ratios close to the best expander efficiencies and unit volumes, and

- independently with one or the other cycle in function of the solar condition or of the heat demand requirements $[1,15]$.

Fig. 1 shows the simplified flowsheet of the SPS prototype of power plant.

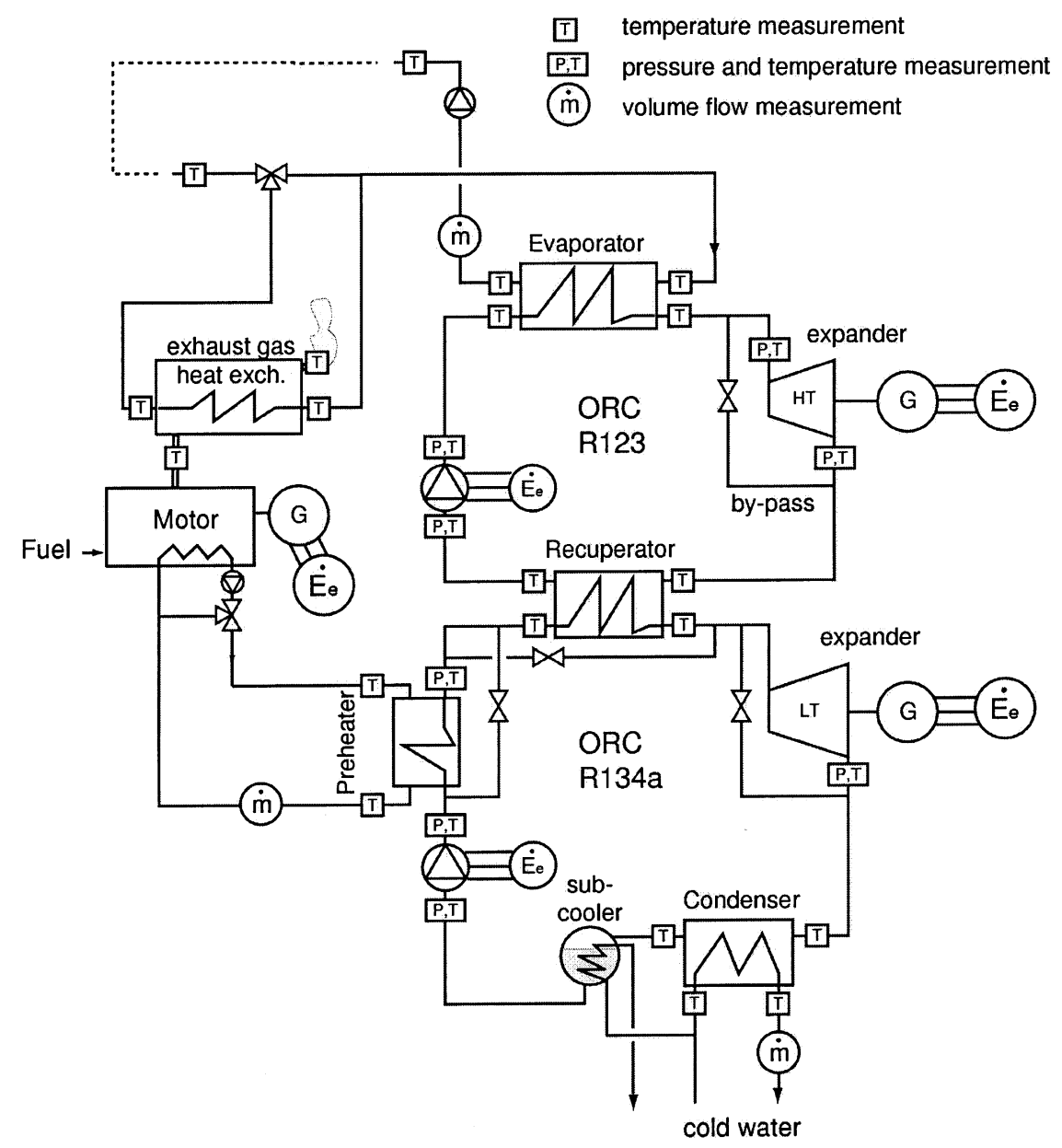

Fig. 1. Simplified flowsheet of the SPS power unit. 
For this prototype unit (Fig. 2), the chosen fluids are HCFC 123 for the topping cycle and HFC 134a for the bottoming cycle.

\subsection{Topping ORC (HCFC123)}

The vapor produced in a (plate) evaporator is either bypassed (during warm-up) or expanded in the high temperature scroll unit HT. The discharged vapor is cooled and condensed in a condenser-evaporator (plate) heat exchanger where it communicates its energy to heat, evaporate and superheat the bottoming cycle fluid. Liquid HCFC123 is pumped by a (membrane piston) pump to feed the evaporator of the topping cycle. The nominal power of the HCFC 123 scroll expandergenerator is $5 \mathrm{kWe}$ corresponding to a $53 \mathrm{~cm}^{3} / \mathrm{rev}$ discharge volume (suction volume in compressor). The built-in volume ratio is 2.3 . In the present setup, the boiling temperature varies between 120 and $150{ }^{\circ} \mathrm{C}$ as a function of the solar radiation.

\subsection{Bottoming ORC (HFC134a)}

The heat recovery from the topping cycle allows the evaporation of the fluid of the bottoming cycle (HFC134a). The flowsheet is almost identical to the one of the topping cycle with however an additional heat exchanger to recover heat from the engine cooling network. The possibility exists to test the latter either in series as a liquid preheater or in parallel to the evaporator. Because of the additional heat rate from the engine, the lower temperature scroll expander is oversized compared to its high temperature counterpart with, in the present design, a nominal power of 8 $\mathrm{kWe}$ (exhaust volume of $72 \mathrm{~cm}^{3} / \mathrm{rev}$ ) for the same built-in volume of 2.3 . Note that step in nominal power is essentially dictated by the range of compressor sizes available on the market. Although previous laboratory tests had been conducted with a separate oil pump to lubricate the expander bearings, a simplification is made here by circulating the oil with the refrigerant. An

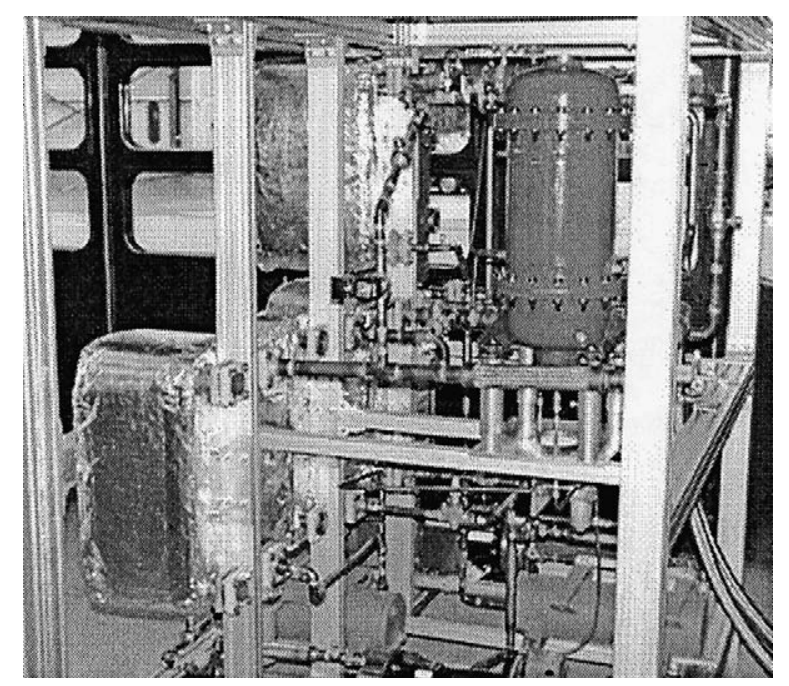

Fig. 2. Power unit with two superposed ORCs tested in laboratory. 
oil separator at evaporator exit (not represented in Fig. 1 recovers the oil to be injected within the hollow expander shaft using the pressure difference available. This arrangement allows operation in the wet expansion domain [16] with limited risks in the event of inadequate control or disturbances of short duration. The efficiency of the separator does not need to be high as some amount of oil is desirable at the expander inlet to contribute to seal the inner gaps during the expansion.

The concept is designed to take advantage, in the future, of an expected increased capability of the expander of the topping cycle to deal with higher inlet temperatures $\left(>150{ }^{\circ} \mathrm{C}\right)$ and therefore increase cycle performance. This is in line with the choice of solar concentrators and of a vacuum insulated collector tube. For simplicity of operation at the prototype stage, pressurized water is being used but a later switch to thermal oil allowing much higher temperatures at moderate pressures is planned. The originality of the concentrators is that they are made of a series of flat mirror bands of calculated and different widths, which can be assimilated to a Fresnel mirror. Each mirror band is fixed with hold-down clip, which allows a handy change in case of breakage. Moreover the open structure with air gaps is expected to reduce the wind forces. ${ }^{2}$

The two lines of collectors installed by a local company are oriented North-South with a tracking system from East to West. They have an active collection area of $100 \mathrm{~m}^{2}$ (Fig. 3). The collected heat rate is of the order of $60 \mathrm{kWth}$ for a solar radiation of $1000 \mathrm{~W} / \mathrm{m}^{2}$.

Because of the need for frequent operation at part load of both the ORCs and the engine, pumps for the ORC are of variable speed and the engine has to have a reasonable efficiency at part load. As gas turbines are both not yet available in the expected power range and not efficient at part load, the choice was made to use a three-cylinder Diesel engine of $15 \mathrm{kWe}$. A good synergy among renewable energy sources could be the use of biodiesel in the future, although no tests have yet been made. Fig. 4 shows the composites (as used in pinch technology) for a case with $50 \mathrm{~kW}$ th delivered by the solar collectors and an operation of the Diesel engine at full power. The top curve (hot composite) represents the cumulated input heat rate and the bottom curve (cold composite) represents the cumulated heat rate received at the temperature level of the ORCs. These composites show the main integration elements, which are:

- (a and $\mathrm{a}^{\prime}$ ): recovery of $19.3 \mathrm{kWth}$ at around $75^{\circ} \mathrm{C}$ on the engine block cooling and boiling at $68{ }^{\circ} \mathrm{C}$ of one part of the bottoming cycle flow (HFC134a),

- (b and $b^{\prime}$ ): boiling at $146^{\circ} \mathrm{C}$ of the HCFC 123 of the topping cycle using the high temperature heat source made of the solar energy as well as of the heat recovered from the combustion gases of the engine, and

- (c and $\mathrm{c}^{\prime}$ ): potential to recover $15 \mathrm{~kW}$ th from about 580 to $160{ }^{\circ} \mathrm{C}$ to complement the heat collected by the solar panels.

Needless to say that the composites are modified as the solar radiation and the motor load vary.

\footnotetext{
${ }^{2}$ The one line of collectors already built in December 1999 at the time of one of the most severe storms of last century survived without any damage.
} 


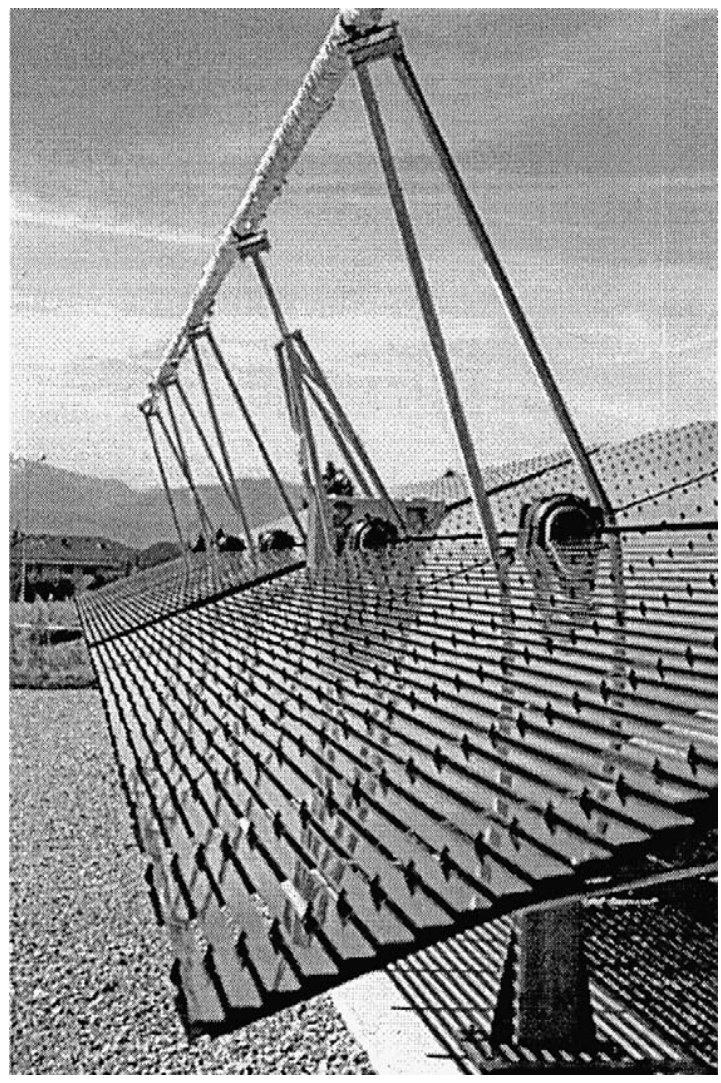

Fig. 3. View of one of the two solar collector lines.

\section{Experimental results}

The first series of tests have been made with the two superposed ORCs alone using electrically heated thermal oil to supply heat to the evaporator of the topping cycle. The bottoming ORC was only supplied through the evaporator-condenser without additional heat supply to replace the engine block heat recovery. The objective was to determine the operational feasible range of heat supply to the topping cycle, the supply temperature as well as the heat rate, which was adjustable to simulate various solar heat supplies.

A second series of tests done in the laboratory included the integration of the engine block cooling heat but without the heat recovery from the gases. A third and limited series of tests have been made in situ with the full integration of the engine and of the solar collectors. It allowed a preliminary validation of the concept of hybrid power plant even though those tests occurred late last fall with a rather weak solar radiation. For each of the tests, the cold source was water at 7 ${ }^{\circ} \mathrm{C}$ with a flow regulation to adapt the condenser temperature of the bottoming cycle. The measured data included the boiling and condensing pressures of both ORCs, the temperatures and pressures at the inlet and outlet of the main components and the electric power at each of the generators as well as the net electricity output. In addition, flowmeters and temperature measurements on the hot and cold streams allowed the determination of the energy balance of the cycles. 


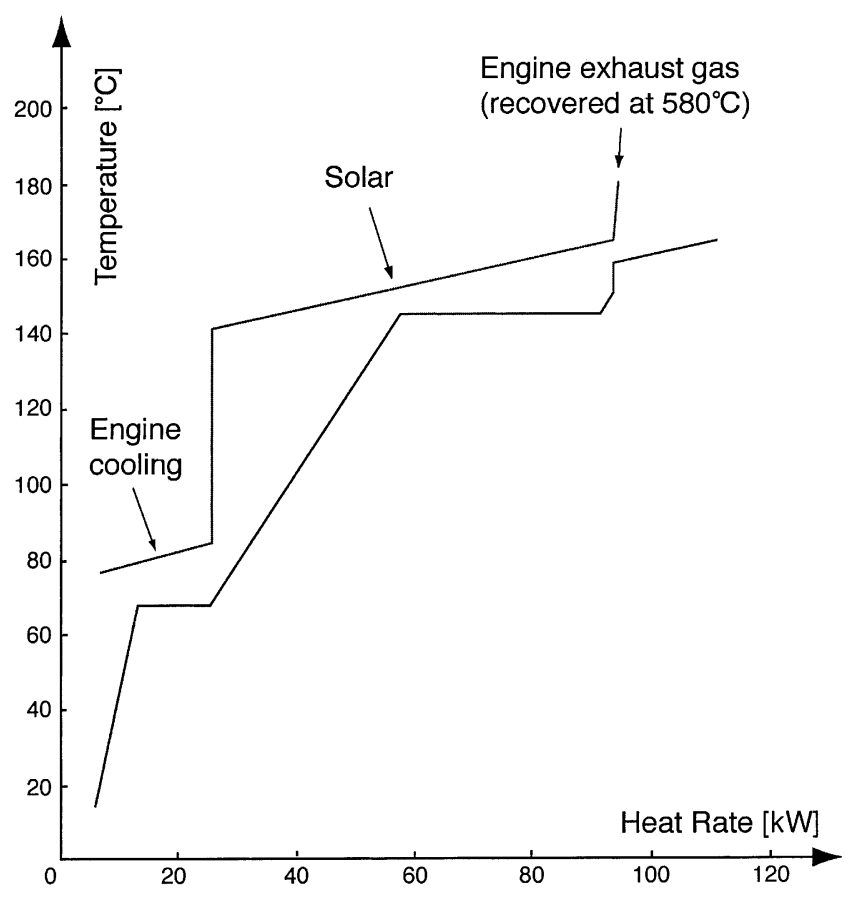

Fig. 4. Diagram of the composites corresponding to a case with engine at its nominal capacity of $15 \mathrm{kWe}$ and 50 $\mathrm{kWth}$ of solar heat rate.

\subsection{Laboratory tests of the superposed ORCs}

The total power range of the laboratory tests was from 3 to $10 \mathrm{kWe}$. The performance of the cycles can be expressed according to two slightly different first law efficiency definitions:

Cumulated electric power produced by the two expanders divided by the sum of the heat and the pump electricity supplied, called efficiency:

$$
\varepsilon_{\mathrm{ORC}}=\frac{\dot{E}}{\dot{M}_{\mathrm{ho}} \Delta h_{\mathrm{ho}}+\dot{E}_{\mathrm{P}}}
$$

or net electrical output (difference between the output of the expanders and the electricity supplied to the pumps) divided by the heat supply, called net efficiency:

$$
\varepsilon_{\mathrm{ORC}}=\frac{\dot{E}_{\mathrm{T}}-\dot{E}_{\mathrm{P}}}{\dot{M}_{\mathrm{ho}} \Delta h_{\mathrm{ho}}}
$$

Figs. 5 and 6 show the variations of efficiencies as well as the power output in function of the heat supplied to the evaporator of the topping cycle for a temperature of heat supply varying between 130 and $165{ }^{\circ} \mathrm{C}$.

The overall superposed cycle efficiency up to $(14.1 \pm 0.2) \%$ is satisfactory for this low power range (up to $10 \mathrm{kWe}$ ) and the relatively low supply temperature (up to $165^{\circ} \mathrm{C}$ ).

Note that for these peak values, the corresponding Carnot efficiency is of the order of $30 \%$. Fig. 7 shows the variation of the exergy efficiency in function of the supply heat rates. Those 


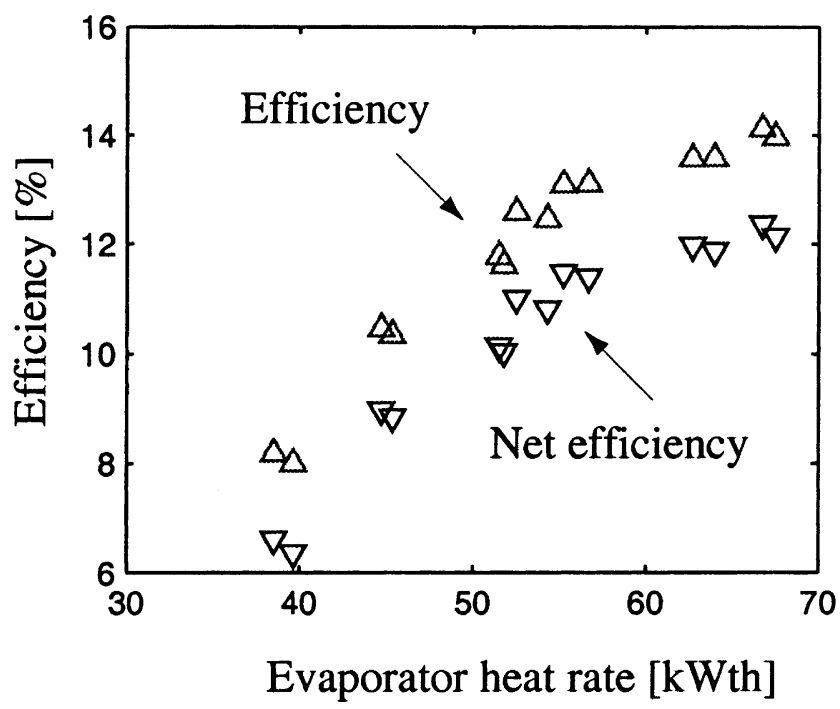

Fig. 5. Efficiencies of the superposed ORCs as for various supply heat rates.

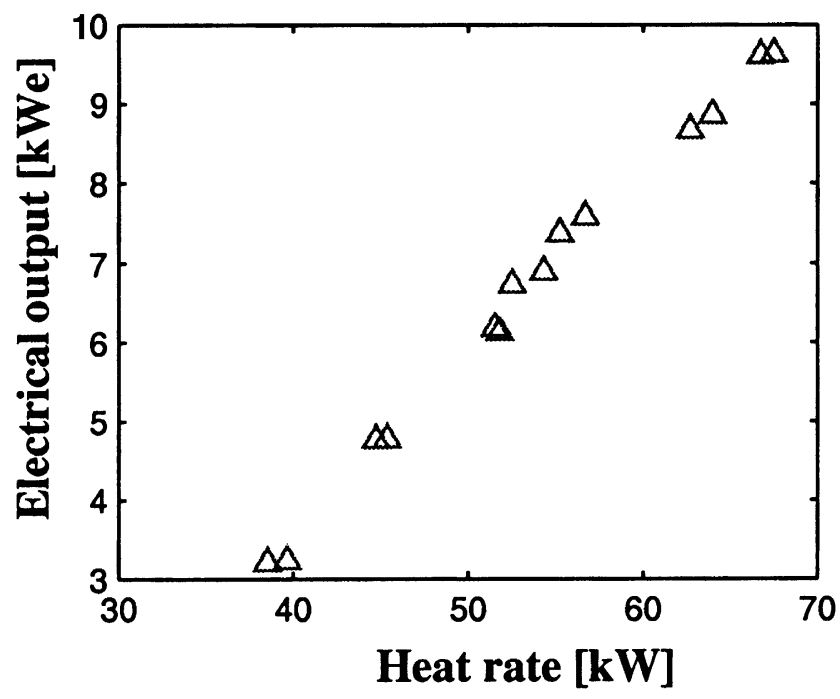

Fig. 6. Electric power outputs for various supply heat rates.

exergy efficiencies are good when compared to data published with other ORCs working within a comparable temperature range [17].

Note that the efficiency decrease at low supply heat rates can be explained by the losses linked to the inadapted pressures at the expander of the bottoming cycle (see Fig. 8). This is due to the fact that, for simplicity, the two generators are directly connected to the grid without any variable speed electronics. This simple and cheap approach imposes gliding pressures with variable loads. Moreover the high amount of oil mixed with the refrigerant increases the boiling temperature in the end phase of evaporation moving the pinch point there. This phenomenon is well known in 


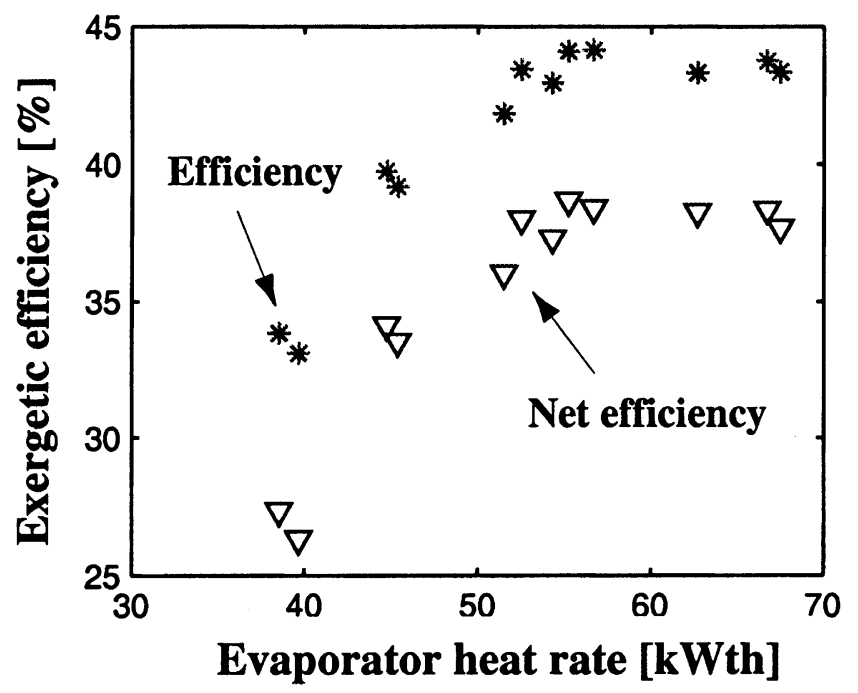

Fig. 7. Exergy efficiencies of the superposed ORCs for various supply heat rates.

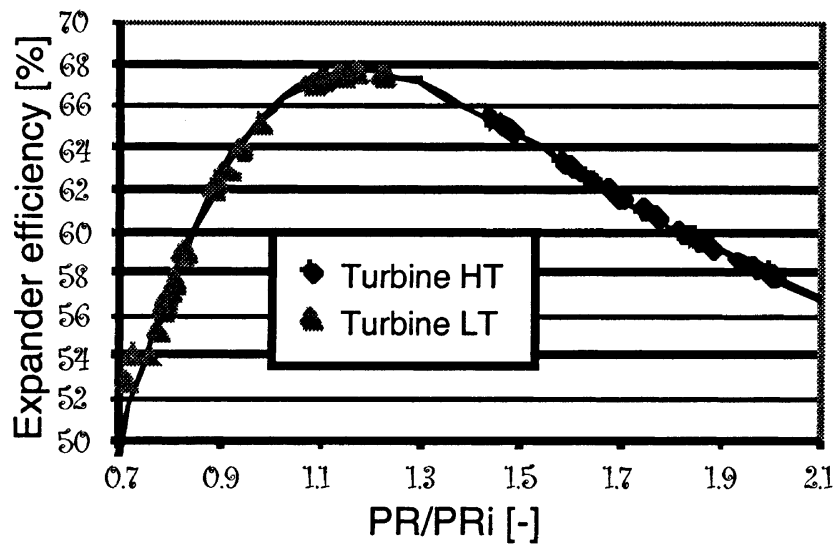

Fig. 8. Electric isentropic efficiencies and operating range of the expanders.

heat pumps and is accompanied by a significant drop in heat transfer with a corresponding drop of the evaporation pressure. This is particularly negative at the evaporator-condenser where the resulting temperature difference is excessive. Solutions to improve this situation are change of evaporator-condenser type (falling film shall-in-tube instead of plate evaporator), introduction of expander speed regulation, separation of the oil at the discharge of the bottoming cycle with a separate oil pump, etc.

Nevertheless these preliminary tests on the superposed cycles allowed a demonstration of the robustness of the present concept, providing some insight on the control characteristics required for an automated operation of the power plant. 


\subsection{Laboratory tests with the ORCs and the integration of the heat supply from the engine} block cooling

For simplicity and safety reasons, ${ }^{3}$ the coupling of the engine with the ORCs was done only through the recovery of the engine block cooling. This was not a major hindrance as the laboratory thermal oil heater had enough power available to simulate the supply from both the solar collectors and the combustion gas cooling over the whole range of expected conditions. The heat rate from the engine block cooling was of $18 \mathrm{kWth}$ for an operation of the engine at $12.8 \mathrm{kWe}$. Fig. 9 shows the variation of the power output from the expanders in function of the topping cycle supply temperature with or without the engine. Note the substantial increase of the system's performance particularly at lower heat rates. This is due to a better adaptation of the pressures at the bottoming expander as a result of the block heat supply. This improvement is however limited by the capacity of the pump and the pinch occurring at the end of evaporation.

\subsection{In situ tests of the complete hybrid power plant}

In situ tests have been done over a period of several months from May to October 2001 on a site at EPFL (Lausanne, Switzerland). This allowed performances to be measured over a broad and variable operational range of conditions. Direct sun radiation varied from day to day between 500 and $800 \mathrm{~W} / \mathrm{m}^{2}$ for a collector area of $100 \mathrm{~m}^{2}$. When used, the power range of the engine varied between 11 and $13 \mathrm{kWe}$, due in particular to variations in the air temperature, and gave a heat recovery of the order of $20 \mathrm{kWth}$ on the engine block and $7 \mathrm{kWth}$ on the exhaust gases. For all tests covering a cumulated duration of $110 \mathrm{~h}$, the power plant produced about $800 \mathrm{kWh}$

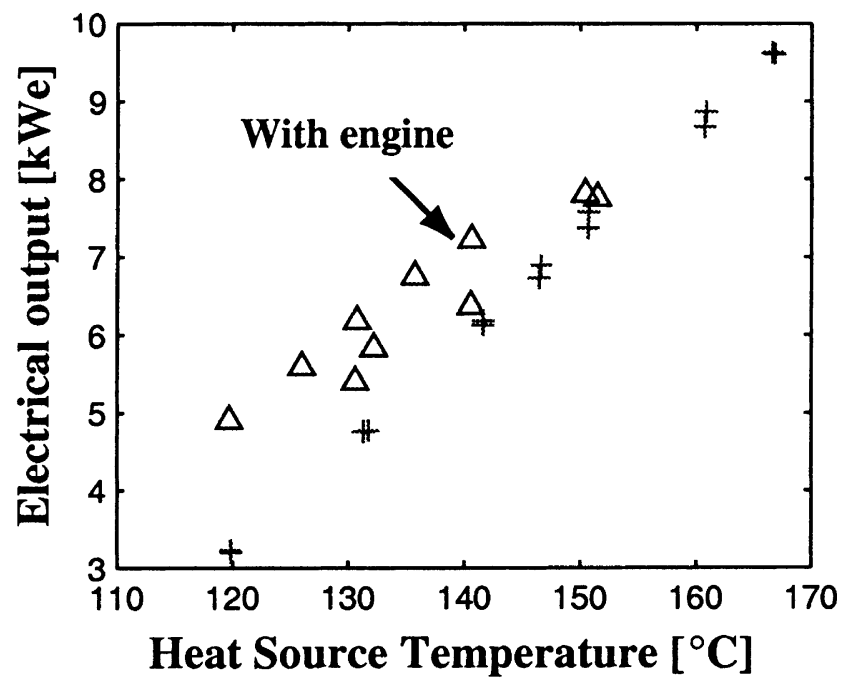

Fig. 9. Electric power produced by the expanders (with or without engine operated at $13 \mathrm{kWe}$ power output).

\footnotetext{
${ }^{3}$ In the laboratory, thermal oil was used instead of pressurized water and an accidental contact between thermal oil and combustion gases was to be avoided.
} 
Table 1

In situ test conditions and number of produced $\mathrm{kWh}$ (Site EPFL-Lausanne)

$\begin{array}{ll}\text { Solar } & \\ \quad \text { Direct solar radiation }\left(\mathrm{W} / \mathrm{m}^{2}\right) & 500-800 \\ \quad \text { Collector area }\left(\mathrm{m}^{2}\right) & 100 \\ \text { Engine } & 11-13 \\ \quad \text { Electrical power }(\mathrm{kWe}) & 20 \\ \text { Engine cooling rate }(\mathrm{kWth}) & 82.5 \\ \quad \text { Cooling temperature }\left({ }^{\circ} \mathrm{C}\right) & 5-7 \\ \quad \text { Combustion gas heat rate }(\mathrm{kWth}) & 120-150 \\ \text { Superposed ORCs } & 7-9 \\ \quad \text { Hot source temperature }\left({ }^{\circ} \mathrm{C}\right) & 500-550 \\ \text { Cold source temperature }\left({ }^{\circ} \mathrm{C}\right) & \\ \quad \text { Condensation pressure }(\mathrm{kPa}) & 110 \\ \text { SPS power plant } & 500 \\ \quad \text { Number of hours }(\mathrm{h}) & \end{array}$

including $500 \mathrm{kWh}$ from the turbines. Some of the operational conditions as well as the results obtained for two operational modes (solar only and hybrid) are summarized in Tables 1 and 2.

Considering the fact there are different input temperature levels for ORCs, it is best to express them exergetically for both operational modes (solar only without engine input or hybrid mode with engine). Curves of ORC exergy efficiencies and electrical energy produced by the scroll turbines are given in Figs. 10 and 11.

The exergy efficiency is the ratio between the net electrical power and the heat exergy (or exergy transformation) of the various heat inputs to the superposed cycles according to

$$
\eta_{\mathrm{ORC}}=\frac{\dot{E}_{\mathrm{T}}-\dot{E}_{\mathrm{P}}}{\dot{M}_{\mathrm{pw}} \Delta k_{\mathrm{pw}}+\dot{M}_{\mathrm{cw}} \Delta k_{\mathrm{cw}}}
$$

The two distinct curves obtained in hybrid mode correspond to a series of measures with differ-

Table 2

In situ test results for two operational points (mode solar only and hybrid, Site EPFL-Lausanne)

\begin{tabular}{lll}
\hline Dates & 05.20 .01 & 08.14 .01 \\
Direct solar radiation $\left(\mathrm{W} / \mathrm{m}^{2}\right)$ & 833 & 742 \\
Operating mode (-) & Solar & Hybrid \\
Collector efficiency $(\%)$ & 57 & 56 \\
Total electrical power (kWe) & 6.52 & 18.57 \\
Turbine electrical power (kWe) & 6.52 & 7.32 \\
Engine electrical power (kWe) & 0 & 11.25 \\
Cycle energy efficiency (First Law) (\%) & 13.7 & 13.67 \\
Cycle exergy efficiency (\%) & 46.57 & 57.26 \\
Overall system efficiency (\%) & 7.74 & 15.88 \\
Fossil efficiency $(\%)$ & - & 41.1 \\
\hline
\end{tabular}




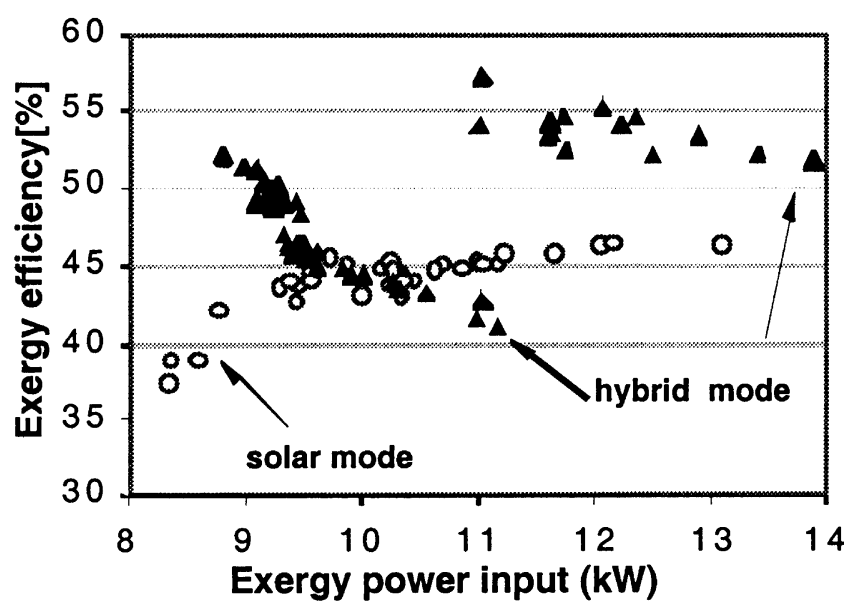

Fig. 10. Exergy efficiency.

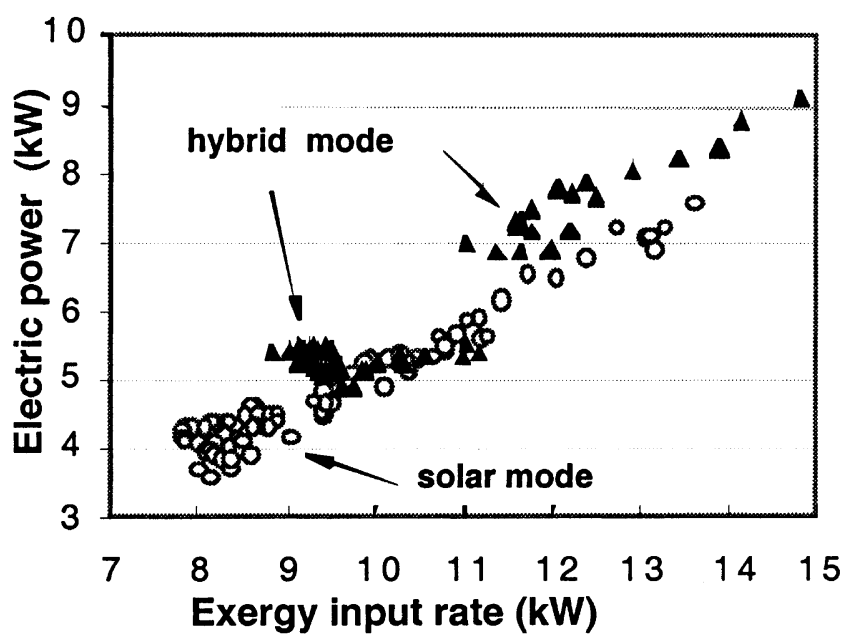

Fig. 11. Electrical power delivered by the scroll expanders.

ent values of solar radiation. Even if a number of improvement opportunities have been detected, the performance reached is encouraging for a thermodynamic conversion cycle in this power range and with such a low level of temperature. The superposed cycle exergy efficiency reached a maximum value of $(46.6 \pm 1.9) \%$ in solar mode only and $(57.3 \pm 2.4) \%$ in hybrid solar mode. The decrease of exergy efficiency observed in hybrid mode can be attributed to losses linked to an increase of the condensing pressure. The latter is due to a limitation of the cooling flow, which was observed following construction works which affected the cooling network.

It is interesting to note that the energy efficiency (First Law) in hybrid mode and referred to the fuel only (total electrical power/fuel LHV) reaches $(41.1 \pm 1.7) \%$, which represents an increase of $50 \%$ compared to the electrical efficiency of $27 \%$ of the original Diesel unit. However the solar electrical efficiency alone (ORC electrical power/solar radiation) is of the order of (7.74 $\pm 0.06) \%$, which is $35 \%$ lower than the $12 \%$ initially expected. 
The tests reported here have been realized in very partial operational conditions of the cycles. Fig. 11 illustrates the load level of the turbines $(9 \mathrm{kWe}$ maximum for an installed power of 12 $\mathrm{kWe}$ ). These operations at partial loads are due to an over sizing of the turbine relative to the solar field and to the fact that the solar field did not yet achieve the expected efficiencies, about $(56 \pm 1) \%$ only for an initial value estimated at $75 \%$ (corresponding to $60 \mathrm{kWth}$ direct solar radiation of $800 \mathrm{~W} / \mathrm{m}^{2}$ ). Moreover the characteristics of the heat exchangers and particularly the evaporator-condenser are very sensitive to oil trapping. The minimum pinch is located at the end of evaporation, which inherently limits the heat transfer capacity. Nevertheless these tests did allow the experimental validation of the concept of hybrid solar plant HSPS and its interest for the solar thermal electric conversion.

\section{Conclusion}

A novel concept of mini-hybrid solar power plant has been partly demonstrated both in laboratory and in situ. Indications so far confirm the robustness of the concept, which should be well adapted to cogeneration in isolated settlements, particularly in the sun belt regions. Laboratory tests have shown adequate behavior over a broad range of conditions including in the presence of large variations of thermal supply. The integration of a thermal Diesel engine to the superposed Organic Rankine Cycles of the thermal solar plant has been successful with reasonable efficiencies considering the relatively low power range of such a pilot plant. Replacing fuel supply by bioDiesel, which still has to be demonstrated, would provide a fully renewable solution with power availability largely independent from atmospheric conditions. The modular nature of the concept with other potential applications of the power units for waste heat recovery should contribute to lowering the production costs and improving economic viability although this aspect was not specifically addressed in the present study. Measured First Law efficiency of electricity production in hybrid mode is of the order of $41 \%$ when considering only the fossil fuel input (total electrical power/LHV of the fuel). This already represents an efficiency increase of close to $50 \%$ compared to the Diesel engine alone.

However due to an oversizing of the turbines and a lower solar collector efficiency than expected, the conversion operated at very partial load and the efficiency in mode "solar only" was only of $7.74 \%$. The latter is $35 \%$ below the expected performance because the operations were far from the expected nominal values of the ORCs. Several power plant components deserve further studies and this is particularly true for the evaporator-condenser and the pumps of the ORCs. Furthermore the likelihood of the future availability of higher temperature turbines or expanders exists to further enhance the potential of such integrated plants. An additional path could be to envisage substituting the thermal engine for a fuel cell (most likely solid oxide fuel cell) when available in the future with their excellent part load characteristics.

\section{Acknowledgements}

The authors would like to acknowledge the financial support provided by the Swiss Federal Office of Energy. They also take this opportunity to express their gratitude to S. Martin who contributed to the completion of some of the tests. 


\section{Appendix A. Experimental error calculations}

The physical data, directly measured, are:

- The temperatures $(\mathrm{K})$ at the inlet and outlet of each component, using thermocouples type $\mathrm{K}$ with $0.02 \%$ relative error.

- The pressures $(\mathrm{kPa})$ at the inlet and outlet of each component, using piezo-resistif sensors $(0-$ $2500 \mathrm{kPa}$ ) with $0.2 \%$ relative error.

- The volumetric flow rates $(1 / \mathrm{min})$ of heat inputs to the superposed cycles, using flow meters type Danfoss with $0.25 \%$ relative error.

- The electric power at each of the generators, using Waft-meters NORMA AC Power Analyzer D5255S with $0.25 \%$ relative error for the turbines and Watt-meters GMC Instrument/CDA P200-057 with $0.50 \%$ error for pumps and motor engine.

- The solar radiation $\left(\mathrm{W} / \mathrm{m}^{2}\right)$ to the flat reflectors, using Pyrometers EPPLEY Model PSP with $0.50 \%$ relative error.

According to the theory of error propagation, errors estimate on the efficiency have been determined by using the following equations:

superposed cycle energy and exergy efficiencies

$$
\begin{aligned}
& \frac{\Delta \varepsilon}{\varepsilon}=\frac{\Delta \dot{E}_{\mathrm{T}}}{\dot{E}_{\mathrm{T}}}+\frac{\Delta \dot{E}_{\mathrm{P}}+\Delta \dot{W}_{\mathrm{ho}}}{\dot{E}_{\mathrm{P}}+\dot{W}_{\mathrm{ho}}} \\
& \frac{\Delta \varepsilon^{\prime}}{\varepsilon^{\prime}}=\frac{\Delta \dot{E}_{\mathrm{T}}+\Delta \dot{E}_{\mathrm{P}}}{\left|\dot{E}_{\mathrm{T}}-\dot{E}_{\mathrm{p}}\right|}+\frac{\Delta \dot{W}_{\mathrm{ho}}}{\dot{W}_{\mathrm{ho}}} \\
& \frac{\Delta \eta}{\eta}=\frac{\Delta \dot{E}_{\mathrm{T}}+\Delta \dot{E}_{\mathrm{P}}}{\left|\dot{E}_{\mathrm{T}}-\dot{E}_{\mathrm{P}}\right|}+\frac{T_{\mathrm{pw}}+T_{\mathrm{c}}}{\left|T_{\mathrm{pw}}-T_{\mathrm{c}}\right|} \cdot \frac{\Delta T_{\mathrm{pw}}}{T_{\mathrm{pw}}}+\frac{\Delta \dot{W}_{\mathrm{pw}}}{\dot{W}_{\mathrm{pw}}}+\frac{T_{\mathrm{cw}}+T_{\mathrm{c}}}{\left|T_{\mathrm{cw}}-T_{\mathrm{c}}\right|} \cdot \frac{\Delta T_{\mathrm{cw}}}{T_{\mathrm{cw}}}+\frac{\Delta \dot{W}_{\mathrm{cw}}}{\dot{W}_{\mathrm{cw}}}
\end{aligned}
$$

where

$$
\frac{\Delta \dot{W}}{W}=\frac{\Delta \dot{M}}{\dot{M}}+\frac{T_{\text {in }}+T_{\text {out }}}{\left|T_{\text {in }}-T_{\text {out }}\right|} \cdot \frac{\Delta T}{T}
$$

solar electrical efficiency

$$
\frac{\Delta \varepsilon_{\mathrm{s}}}{\varepsilon_{\mathrm{s}}}=\frac{\Delta \dot{E}_{\mathrm{T}}}{\dot{E}_{\mathrm{T}}}+\frac{\Delta G}{G}
$$

fossil energy efficiency

$$
\frac{\Delta \varepsilon_{\mathrm{f}}}{\varepsilon_{\mathrm{f}}}=\frac{\Delta \dot{E}_{\mathrm{M}}+\Delta \dot{E}_{\mathrm{T}}}{\dot{E}_{\mathrm{M}}+\dot{E}_{\mathrm{T}}}+\frac{\Delta \dot{M}_{\mathrm{f}}}{\dot{M}_{\mathrm{f}}}
$$


where

$$
\frac{\Delta \dot{M}_{\mathrm{f}}}{\dot{M}_{\mathrm{f}}}=\frac{\Delta \dot{M}_{\mathrm{pw}}}{\dot{M}_{\mathrm{pw}}}+2 \frac{\Delta T}{T}\left(\frac{1}{\left|1-T_{\mathrm{s}} / T_{\mathrm{pw}}\right|}+\frac{1}{\left|1-T_{\mathrm{eg}} / T_{\mathrm{g}}\right|}\right)
$$

\section{References}

[1] Favrat D. Concept de centrale électrothermosolaire alpine. In: Faist A, editor. CISBAT’95. 1995: EPFL; 1995. p. 67-72.

[2] Allani Y, Favrat D, von Spakovsky M. $\mathrm{CO}_{2}$ mitigation through the use of hybrid solar-combined cycles. Energy Conversion Mgmt 1997;(38):661-7.

[3] Buck R, Goebel O, Koehne R, Tanurie R, Trieb F. Advanced solar/fossil combined power plants. In: Chen K, editor. Proceedings of The International Energy and Environment Conference, Shanghai, vol. 1. 1998. p. 423-34.

[4] Kolb GJ. Evaluation of power production from the solar electric generating system at Kramer junction 1988 to 1993. In: Stine WB, editor. Proceedings of ASME International Solar Energy Conference, Hawai. 1997. p. 499-504.

[5] Allani Y, Favrat D. Concept Global d'une Nouvelle Centrale Solaire à Cycle Combiné Dual Fuel. Entropie 1991;27(164/165):121-2.

[6] Kane M, Favrat D. Approche de conception et d'optimisation de centrale solaire intégrée à cycle combiné inspirée de la méthode du pincement (part I and II). Int J Therm Sci 1999;38(6):501-24.

[7] Kane M, Favrat D et al. Thermoeconomic analysis of advanced solar-fossil combined cycle power plants, ECOS, Int. J Appl Thermodynamics 2000;3(4):191-8.

[8] Pilkington Solar International GmbH. Status Report on Solar Thermal Power Plants. ISBN 3-9804901-0-6. January 1996. Mühlengasse 7,D-50667, Köln, Germany.

[9] Goswami OY. Solar energy and the environment. In: Szargut J, editor. ASME 1993 International Conference on Energy Systems and Ecology, Cracow, Poland, vol. 1. 1993. p. 77-85.

[10] Price HW, Whitney DD, Beebe HI. SMUD Kokhala Power Tower Study. In: Davidson JH, Chavez J, editors. Proceedings of the 1996 international Solar Energy Conference, San Antonio, TX. 1996. p. 273-9.

[11] Koai K, Lior N, Yeh H. Performance analysis of a Solar-powered Rankine Cycle with a novel 30 HP turbine. Solar Energy 1984;32(6):753-64.

[12] Lior N. Advanced energy conversion to power. Energy Conversion Mgmt 1997;38(10-13):941-55.

[13] Kane M. Intégration et Optimisation thermoéconomique et environomique de centrales thermiques solaires hybrides. PhD Thesis No. 2565. Lausanne, Switzerland: EPFL, 2002.

[14] Zanelli R, Favrat D. Experimental investigation of a hermetic scroll expander-generator. In: Soedel W, editor. 12th International Compressor Engineering Conference, Purdue, USA. 1994. p. 459-64.

[15] Kane M, Brand F, Favrat D. Centrale solaire hybrid. Final Report to Swiss Federal Office of Energy, 1999.

[16] Kane M, Favrat D. Nouveau concept de lubrification appliqué à une turbine scroll au sein d'un cycle de Rankine. Internal Report LENI no. 99.09i. Lausanne, Switzerland: EPFL, 1999.

[17] VDI (Verein Deutscher Intgenieure): ORC-HP-Technology, Working fluid Problems in: VDI Bericht 539, VDIVerlag Dusseldorf (1984). 